\title{
Current possibilities in occlusal caries management
}

\author{
Hrvoje Jurić \\ Department of Pediatric and Preventive \\ Dentistry, School of Dental Medicine \\ University of Zagreb and Clinical Hospital \\ Center Zagreb, Clinic for Dentistry \\ Zagreb, Croatia \\ Corresponding author: \\ Hrvoje Jurić \\ Department of Pediatric Dentistry \\ School of Dental Medicine \\ University of Zagreb \\ Gundulićeva 5 \\ 10000 Zagreb \\ Croatia \\ juric@sfzg.hr \\ Tel.: + 38514802102 \\ Fax.: + 38514802159 \\ Received: 1 April 2013 \\ Accepted: 16 May 2013 \\ Copyright (C) 2013 by \\ Academy of Sciences and Arts \\ of Bosnia and Herzegovina. \\ E-mail for permission to publish: \\ amabih@anubih.ba
}

Dental caries is a multifactorial disease that affects most populations throughout the world and it is still the primary cause of oral pain and tooth loss. The occlusal surfaces of posterior teeth are the most vulnerable sites for dental caries due to their anatomy. Therefore, the aim of the following article is to summarize current knowledge on occlusal caries development and the possibilities of its prevention. Although the overall caries rate today has fallen for populations in industrialized countries, the rate of occlusal surface caries has not decreased. This may be explained with fact that topically applied fluorides and their mode of action prevent caries better on smooth than on occlusal surfaces. As we know, tooth decay of first permanent molars causes a great deal of different short and long term difficulties for patients. Therefore, there is a continuous need for implementation of programs for caries prevention in permanent teeth. Nowadays, we like to treat our patients by minimally invasive methods. A very important step in our effective preventive treatment is sealing pits and fissures as a cornerstone of occlusal caries management. Reliable assessment of caries activity is also very important for defining treatment needs and plans. A very important decision, which should be made during occlusal caries management, is the selection of restorative material according to the treatment plan. Conclusion. Current possibilities in occlusal caries prevention and management are very effective. Therefore, dentists today do not have any excuse for avoiding the philosophy of Minimally Invasive Dentistry, especially when we talk about caries management of occlusal surfaces in permanent molars.

Key words: Occlusal caries, Prevention, Pit and fissure sealing.

\section{Introduction}

Dental caries is a multifactorial disease that affects most populations throughout the world and it is still the primary cause of oral pain and tooth loss (1). From different epidemiological studies we know that $60-90 \%$ of the total population suffers from dental caries and problems with caries start in very young patients with primary teeth $(2,3)$.

On the other hand, over past decades the common consensus from many reports worldwide was that dental caries had declined significantly and was continuing to decline in the population. The dental community has prided itself on its efforts that have reduced dental caries, including use of systemic and topical fluorides, toothpastes, sealants, improvements in diet, oral health education and dental care $(4,5)$. There are, however, some recent studies that report alarming increases in caries incidence. These increases are in children and adults, 
primary and permanent teeth, and include coronal and root surfaces (6-8). The emerging public health issues are related to disparities in the prevalence and treatment of dental caries. An important facet is the social impact of differences in dental caries for specific groups of individuals throughout the world. The increases in caries appear to occur in lower socioeconomic groups, new immigrants and children. While the causes of these increases in caries are unclear, it is possible that the benefits of prevention are not reaching these groups.

The dental hard tissues - enamel, dentin and cementum - form relevant solid surfaces which are coated by a pellicle, to which microbial cells attach (9). Saliva modifies the complex interplay between the teeth and the surrounding biofilm: the secretion, flow rate and composition of saliva are dynamic parameters that are controlled by the physiological and pathological conditions of the host (10). The bacteria in the biofilm are metabolically active and they cause fluctuations in the $\mathrm{pH}$ of saliva. These fluctuations induce the loss of mineral from the tooth, when the $\mathrm{pH}$ decreases, or gain of minerals when the $\mathrm{pH}$ increases. The localized destruction of the hard tissues, the caries lesion, is the sign or symptom of the disease (1). Occlusal surfaces of posterior teeth are the most vulnerable sites for dental caries due to their anatomy, favoring plaque retention and maturation (11). Although the overall caries rate has fallen for populations in industrialized countries, the rate of caries lesions in pits and fissures has not decreased at the same time (12). As we see, young permanent teeth are especially vulnerable, and early progression of occlusal caries lesions in first permanent molars causes a great deal of different short and long term difficulties for patients $(13,14)$. One of the main reasons for the less effective occlusal caries prevention today, in the so-called "post-fluoride" generation, is the fact that topically applied fluorides prevent caries better on smooth surfaces than in pits and fissures. That makes changes in current epidemiologic situation and it is recognized like increase of new primary lesions on occlusal surface (15). Therefore, there is a continuous need for implementation of effective programs to prevent caries in the pits and fissures of the permanent molars of schoolchildren.

\section{Occlusal caries lesions}

The term fissure caries was earlier used to describe the caries lesions found in pits and fissures. This definition was based on the assumption that the high incidence of caries lesions in molar pits and fissures was directly related to poor cleaning accessibility to these surfaces. Occlusal pits and fissures vary in shape but are generally narrow (about $0.1 \mathrm{~mm}$ wide), with invaginations or irregularities where bacteria and food are mechanically retained. Saliva cannot reach the base of the fissures and those areas cannot be properly cleaned mechanically. Toothbrush bristle is too large (diameter 0.2 $\mathrm{mm}$ ) to penetrate most fissures. The thickness of enamel at the base of deep fissures is minimal and in many cases the fissures extend practically to the dentinal surface (16).

Present knowledge indicates that the narrow fissures in young permanent molars are not the focus for the caries initiation per se. Two factors have been considered of importance for plaque accumulation and caries initiation on occlusal surfaces: the stage of eruption or functional usage of teeth and surface specific anatomy $(17,18)$. A carious lesion initiates as a local process at the entrance, along to deep fissures as plaque accumulates within the slopes of the cusps on occlusal surfaces. These sites offer protection against physical wear, and favor the formation of micro-cavities that further improve local conditions for oral bacteria, whereas the deepest part of the fissure usually har- 
bors non-vital bacteria or calculus (19). The growth and proliferation of bacteria accelerate demineralization and destruction of occlusal surfaces (1). These areas often become stagnated due to the demineralization/remineralization process and can be clinically identified. Therefore, for conventional pit and fissure caries, the use of the more accurate term "occlusal caries" is suggested (20).

\section{Development of occlusal caries management}

We can provide for prevention of occlusal caries on different levels and using different approaches. At the very beginning of occlusal caries prevention Hyatt suggested the prophylactic odontotomy (21). During this procedure small superficial occlusal cavities were made in pits and fissures and restored with amalgam. After that, Boedecker's first suggestion was that for preventive reasons we can undertake prophylactic restoration with oxyphosphate cements on occlusal surface. Finally, for the same preventive reasons, he suggested "eradication" of occlusal enamel fissures. Using this technique, the slopes of the cusps were reduced in order to ensure adequate accessibility of the pit and fissure system during teeth brushing and successful plaque removal from the occlusal surface (22). When we look back, we realize that those technique had two main disadvantages. Both techniques in the end sacrifice sound enamel and their preventive effectiveness has never been proven by any clinical study. Nowadays, we like to treat our patients using minimally invasive methods or if possible, non-invasively. Therefore, those old techniques for prevention of occlusal caries have only historical value.

What is the scientific and professional background of the modern "Minimally Invasive Dentistry" (MID) philosophy? The goal of MID is to preserve healthy tooth structure as much as possible. It focuses on prevention, remineralization, and minimal restorative intervention. Using scientific advances, MID allows dentists to perform the least amount of dentistry needed while never removing more of the tooth structure than is required to restore teeth to their normal condition. The development of adhesive dentistry and scientific progress in understanding the nature of caries has enabled dentists to do more than simply remove and replace diseased tissue. The new paradigm of MID can be emphasized of following the concept presented by Tyas and coworkers (23): early caries diagnosis; the classification of caries depth and progression; the assessment of individual caries risk; the reduction of cariogenic bacteria; the arresting of active lesions; the remineralization and monitoring of non-cavitated arrested lesions; the placement of restorations in teeth with cavitated lesions (minimal cavity design); the repair rather than the replacement of defective restorations; assessing disease management outcomes at pre-established intervals.

\section{Current approach in occlusal caries prevention}

\section{Sealing of sound occlusal enamel}

A non-invasive approach is always imperative when we talk about prevention in dentistry. Therefore, professional teeth cleaning with fluoridated paste and application of fluoride varnish on the occlusal surface or sealing of the pits and fissures system are techniques which should be recommended for everyday practice. When we talk about sealing of sound pits and fissures, we can actually distinguish two different levels of intervention and we can recognize preventive and therapeutic sealant application.

When we do preventive sealant application we treat completely sound occlusal enamel without any clinical signs of demineralization. The therapeutically oriented approach of sealant application means that we 
have the clinically visible first signs of enamel demineralization ("white spots") and that without any invasive intervention we seal that enamel (24). One of the main problems is that pit and fissure sealing must be applied very early, immediately after tooth eruption, when the cooperative ability of children could be very low. In this case, some anatomical factors and lack of proper isolation may reduce the retention of sealants and that decreases efficacy of occlusal caries prevention.

\section{Enamel/dentin lesions sealing}

In recent years we have increased therapeutic sealant application over incipient caries to prevent progression of the lesion $(25,26)$. In this case, the most important fact is how many viable bacteria are left behind that can induce further progression of caries lesion. The second important fact is the adequate adherence of sealing material. Theoretically, good adhesion of sealing material cuts off any possible influence from the oral cavity, the metabolic activity of cariogenic microorganisms is reduced and caries progress stops. Research shows that the application of sealants on fissures with questionably cavitated lesion ("sticky fissures on probing") resulted in the reduction of viable bacteria, compared with unsealed fissures (27). Use of acid etching as a pretreatment also killed between $75-95 \%$ of all bacteria in the pits and fissures $(28,29)$. Analyzing those data, and according to the modern philosophy of MID, it is very obvious that cutting away enamel caries lesions is not necessary.

Sealing of cavitated pits and fissure lesions in dentin is still a procedure which should be better investigated. A few reports show that arresting of dentin lesion is possible, but we believe that the clinical outcome of the treatment is still unpredictable (30). On the other hand, another study shows that sealed caries fissures showed significantly more microleakage and insufficient sealant penetration depth than sound fissures. Neither the use of an adhesive nor its intermediate curing influenced the microleakage score and the penetration ability of sealants (31). Therefore, we still wait for more in vitro and in vivo studies which would confirm the efficacy and reliability of dentin lesion sealing. In the meantime, when we want to deal with pit and fissure dentin lesions we should stick to procedures such as "preventive resin restorations" (PRR). This restorative approach for occlusal caries was introduced by Simonsen and Stallard and was indicated for small cavitated lesions of occlusal surfaces extending up to the dentin level $(32,33)$. In this method cavity preparation is minimal and limited to the removal of the local caries lesion. The cavity is then restored with composite resin or glass ionomer cement, before the sealant is applied over the edges of the filled cavity, also covering the remaining pits and fissures.

Simonsen classified preventive resin restorations into 3 categories: type 1 does not penetrate the enamel. Type 2 involves a restorative procedure in the enamel and replacement of lost tooth structure with sealing of the adjacent unprepared pits and fissures accomplished using a flowable resin composite. Type 3 is suggested if the lesion has emerged up to the dentin level. Two materials are used - one to restore and one to prevent future caries attack (34). For the underlying filling material we can use composite resin (flowable or standard) or glass ionomer cement (35). The second material seals the complete fissure and it should be made with composite resin.

\section{Diagnostics of occlusal caries and decision making}

Caries diagnosis is a process which can be considered as a three-step procedure: detection of the lesion, assessment of the severity of the lesion and assessment of the lesion activity (36). Accurate and reliable assessment 
of caries activity is important for determining appropriate treatment needs and establishing an adequate treatment plan (37). From a clinical point of view, caries lesions can be classified as progressive (active) or non-progressive (inactive). If the progression of the lesion is somehow limited, the terms "arrested" or "chronic" can be used. Assessment of the activity of lesions was introduced in a set of clinical caries diagnostic criteria (38). "Nyvad criteria" are based on the physical properties of the surface reflection and texture of early lesions, with chalky and rough lesions being active, and smooth, shiny surfaces being inactive or arrested. The color of the lesion can also be used to make the distinction between arrested and active, as the surface enamel of arrested lesions takes minerals from surrounding fluids, while active lesions retain their white appearance. Active non-cavitated lesions have a higher risk of progressing to a cavity than the same inactive lesions. According to this diagnostic criteria, decision making and establishing of treatment plan is easier and the clinical outcome more predictable. The second diagnostic criteria used very often are the International Caries Detection and Assessment System (ICDAS). This system was developed to create an integrated definition of dental caries and a uniform system to measure the caries process (39). Today we also have ICDAS II, the updated modification of the original criteria (40). The criteria for the ICDAS classification were and have features associated with the "Nyvad criteria" and we can say that the assessment of caries activity is today the cornerstone for decision-making in occlusal caries management.

\section{Materials for pit and fissure sealing}

A very important decision during occlusal caries management is the selection of restorative material for pit and fissure sealing. Many different in vitro and in vivo studies have been undertaking and analyzing those results, it may be concluded that resin-based sealants are still the gold standard and best choice for everyday clinical practice (41, 42). Other materials used for pit and fissure sealing are less effective than resin-based sealants (43). However, some other studies confirm that "alternative" materials, such as glass ionomer cements, can also be very effective for pit and fissure sealing in situations when we need to seal partially erupted molars and have difficulties in proper tooth isolation (44).

\section{Conclusion}

Current possibilities in occlusal caries management, as we mentioned in the text above, are great and very effective in preventive and therapeutic approaches, as many different studies confirm (45), especially when we stress the fact that the incidence of caries on occlusal surfaces has increased last two decades in comparison of caries on smooth surfaces. Therefore, dentists today do not have any good excuse for avoiding the philosophy of MID, especially when we talk about prevention and restorative intervention on occlusal surfaces of permanent premolars and molars. From fluorides to resin-based sealants and glass ionomer cements, we have a large number of different possibilities, techniques and materials, to prevent the loss of hard dental tissue. This way of thinking is easy to understand when we consider the fact that any cavitation is the irreversible loss of hard dental tissue which must be replaced with biological inferior material, as all dental restorative materials available today.

Conflict of interest: The author declares that he has no conflict of interest.

\section{References}

1. Fejerskov O, Kidd EAM, Nyvad B, Baelum V. Defining the disease: an introduction. In: Fejerskov 
O, Kidd EAM, editors. Dental Caries The Disease and its Clinical Management. 2nd ed. Oxford: Blackwell Munksgaard Ltd; 2008. p. 3-6.

2. Yabao RN, Duante CA, Velandria FV, Lucas M, Kassu A, Nakamori M, et al. Prevalence of dental caries and sugar consumption among 6-12 year old schoolchildren in La Trinidad, Benquet, Philippines. Eur J Clin Nutr. 2005;59(12):1429-38.

3. Bagramian RA, Garcia-Godoy F, Volpe AR. The global increase in dental caries. A pending public health crisis. Am J Dent. 2009 Feb;22(1):3-8.

4. Lauris JR, da Silva Bastos R, de Magalhaes Bastos JR. Decline in dental caries among 12-yearold children in Brazil, 1980-2005. Int Dent J. 2012;62(6):308-14.

5. Lussi A, Hellwig E, Klimek J.Fluorides - mode of action and recommendations for use. Schweiz Monatsschr Zahnmed. 2012;122(11):1030-42.

6. Prakash P, Subramaniam P, Durgesh BH, Konde S. Prevalence of early childhood caries and associated risk factors in preschool children of urban Bangalore, India: A cross-sectional study. Eur J Dent. 2012;6(2):141-52.

7. Tubert-Jeannin S, Leger S, Manevy R. Addressing children's oral health inequalities: caries experience before and after the implementation of an oral health promotion program. Acta Odontol Scand. 2012;70(3):255-64.

8. Mamai-Homata E, Topitsoglou V, Oulis C, Margaritis V, Polychronopoulou A. Risk indicators of coronal and root caries in Greek middle aged adults and senior citizens. BMC Public Health. 2012;12:484

9. Kidd EA, Fejerskov O. What constitutes dental caries? Histopathology of carious enamel and dentin related to the action of cariogenic biofilms. J Dent Res. 2004;83 Spec No C:C35-8.

10. Bardow A, Lagerlöf B, Nauntofte B, Tenovuo J. The role of saliva. In: Fejerskov O, Kidd EAM, editors. Dental Caries The Disease and its Clinical Management. 2nd ed. Oxford: Blackwell Munksgaard; 2008. p.189-207.

11. Ripa LW. Sealants revisited: an update of the effectiveness of pit-and-fissure sealants. Caries Res. 1993;27(Suppl 1):77-82.

12. Marthaler TM. Changes in dental caries 19532003. Caries Res. 2004;38:173-81.

13. Batchelor PA, Sheiham A. Grouping of tooth surfaces by susceptibility to caries: a study in 5-16 year-old children. BMC Oral Health. 2004;4:2.

14. Sheiham A, Sabbah W. Using universal patterns of caries for planning and evaluating dental caries. Caries Res. 2010;44:141-50.
15. McComb D, Tam LE. Diagnosis of occlusal caries: Part I. Conventional methods. J Can Dent Assoc. 2001;67(8):454-7.

16. Newbrun E. Cariology. 3rd ed. Chicago, Illinois: Quintessence Publishing Co, Inc; 1989.

17. Carvalho JC, Ekstrand KR, Thylstrup A. Dental plaque and caries on occlusal surfaces of first permanent molars in relation to stage of eruption. J Dent Res. 1989;68(5):773-9.

18. Carvalho JC, Thylstrup A, Ekstrand KR. Results after 3 years of non-operative occlusal caries treatment of erupting permanent first molars. Community Dent Oral Epidemiol. 1992;20(4):187-92.

19. Ekstrand KR, Bjørndal L. Structural analyses of plaque and caries in relation to the morphology of the groove-fossa system on erupting mandibular third molars. Caries Res. 1997;31(5):336-48.

20. Carvalho JC, Ekstrand KR, Thylstrup A. Results after 1 year of non-operative occlusal caries treatment of erupting permanent first molars. Community Dent Oral Epidemiol. 1991;19(1):23-8.

21. Hyatt TP. Prophylactic odontotomy. The cutting into the tooth for prevention of disease. Dental Cosmos. 1923;65:234-41.

22. Boedecker CF. Enamel fissure eradication. NY State Dent J. 1964;30:149-54.

23. Tyas MJ, Anusavice KJ, Frencken JE, Mount GJ. Minimal intervention dentistry: a review. FDI Commission Project 1-97. Int Dent J. 2000;50(1):1-12

24. Courson F, Velly AM, Droz D, Lupi-Pégurier L, Muller-Bolla M. Clinical decision on pit and fissure sealing according to the occlusal morphology. A descriptive study. Eur J Paediatr Dent. 2011;12(1):43-9.

25. Welbury R, Raadal M, Lygidakis NA; European Academy of Paediatric Dentistry. EAPD guidelines for the use of pit and fissure sealants. Eur J Paediatr Dent. 2004;5(3):179-84.

26. Feigal RJ, Donly KJ. The use of pit and fissure sealants. Pediatr Dent. 2006;28(2):143-50.

27. Going RE, Loesche WJ, Grainger DA, Syed SA. The viability of microorganisms in carious lesions five years after covering with a fissure sealant. J Am Dent Assoc. 1978;97(3):455-62.

28. Jensen OE, Handelman SL. Effect of an autopolymerizing sealant on viability of microflora in occlusal dental caries. Scand J Dent Res. 1980;88(5):382-8.

29. Kramer PF, Zelante F, Simionato MR. The immediate and long-term effects of invasive and noninvasive pit and fissure sealing techniques on the microflora in occlusal fissures of human teeth. Pediatr Dent. 1993;15(2):108-12. 
30. Mertz-Fairhurst EJ, Schuster GS, Fairhurst CW. Arresting caries by sealants: results of a clinical study. J Am Dent Assoc. 1986;112(2):194-7.

31. Hevinga MA, Opdam NJ, Frencken JE, Bronkhorst EM, Truin GJ. Can caries fissures be sealed as adequately as sound fissures? J Dent Res. 2008;87(5):495-8.

32. Simonsen RJ, Stallard RE. Sealant-restorations utilizing a diluted filled composite resin: one year results. Quintessence Int Dent Dig. 1977;8(6):77-84.

33. Ripa LW, Wolff MS. Preventive resin restorations: indications, technique, and success. Quintessence Int. 1992;23(5):307-15.

34. Simonsen RJ. Preventive resin restorations and sealants in light of current evidence. Dent Clin North Am. 2005;49(4):815-23.

35. Garcia-Godoy F. The preventive glass ionomer restoration. Quintessence Int. 1986;17(10):617-9.

36. Ekstrand KR, Ricketts DN, Kidd EA. Occlusal caries: pathology, diagnosis and logical management. Dent Update. 2001;28:380-7.

37. Ekstrand KR, Ricketts DN, Longbottom C, Pitts NB. Visual and tactile assessment of arrested initial enamel carious lesions: an in vivo pilot study. Caries Res. 2005;39(3):173-7.

38. Nyvad B, Machiulskiene V, Baelum V. Reliability of a new caries diagnostic system differentiating between active and inactive caries lesions. Caries Res. 1999;33(4):252-60.

39. Pitts NB, Stamm J. International Consensus Workshop on Caries Clinical Trials (ICW-CCT)
Final Consensus Statements: Agreeing Where the Evidence Leads. J Dent Res. 2004;83:125-8.

40. Ismail AI, Sohn W, Tellez M, Amaya A, Sen A, Hasson $\mathrm{H}$, et al. The International Caries Detection and Assessment System (ICDAS): an integrated system for measuring dental caries. Community Dent Oral Epidemiol. 2007;35(3):170-8.

41. Eliades A, Birpou E, Eliades T, Eliades G. Selfadhesive restoratives as pit and fissure sealants: A comparative laboratory study. Dent Mater. 2013 May 10. doi:pii: S0109-5641(13)00089-4. 10.1016/j. dental.2013.04.005. [Epub ahead of print]

42. Souza-Junior EJ, Borges BC, Montes MA, Alonso RC, Ambrosano GM, Sinhoreti MA. Influence of etching time and bonding strategies on the microshear bond strength of self- and light-cured pit-andfissure sealants. Braz Dent J. 2012;23(5):477-83.

43. Kühnisch J, Mansmann U, Heinrich-Weltzien R, Hickel R. Longevity of materials for pit and fissure sealing--results from a meta-analysis. Dent Mater. 2012;28(3):298-303.

44. Antonson SA, Antonson DE, Brener S, Crutchfield J, Larumbe J, Michaud C, et al. Twenty-four month clinical evaluation of fissure sealants on partially erupted permanent first molars: glass ionomer versus resin-based sealant. J Am Dent Assoc. 2012;143(2):115-22.

45. Simonsen RJ, Neal RC. A review of the clinical application and performance of pit and fissure sealants. Aust Dent J. 2011;56:(1 Suppl):45-58. 